\title{
Introduction of Basic Dermatologic Ultrasound in Undergraduate Medical Education
}

Authors

Affiliations
F. Alfageme ${ }^{1}$, E. Cerezo ${ }^{2}$, I. S. Fernandez ${ }^{1}$, R. Aguilo ${ }^{3}$, A. Vilas-Sueiro ${ }^{4}$, G. Roustan

${ }^{1}$ Dermatology, Hospital Puerta de Hierro, Madrid, Spain

${ }^{2}$ Calle Fracisco Silvela \#124, lo 3, Madrid, Spain

${ }^{3}$ Laboral Medicine, Asepeyo, Madrid, Spain

${ }^{4}$ Dermatology, Complejo Hospitalario Universitario Ferrol, Ferrol, Spain
Key words

$\checkmark$ undergraduate medical education

- dermatologic ultrasound

- ultrasonography in medical education received $\quad 13.06 .2016$

accepted $\quad 21.10 .2016$

Bibliography

DOI http://dx.doi.org/

10.1055/s-0042-120273

Ultrasound International Open

2016; 2: E136-E139

(c) Georg Thieme Verlag KG

Stuttgart · New York

ISSN 2199-7152

\section{Correspondence}

\section{Dr. Fernando Alfageme, MD,}

\section{PhD}

Dermatology

Hospital Puerta de Hierro

Av Manuel de Falla 1

28032 Madrid

Spain

Tel.: + 34/914/997 708

Fax: +34/914/326 521

feralfarol@yahoo.es

\section{Abstract \\ $\nabla$}

Purpose: Teaching ultrasound procedures to undergraduates has recently been proposed to improve the quality of medical education. We address the impact of applying standardized dermatologic ultrasound teaching to our undergraduates.

Materials and Methods: Medical students were offered an additional theoretical and practical seminar involving hands-on ultrasound dermatologic ultrasound during their mandatory dermatology practical training. The students' theoretical knowledge and dermatologic ultrasoud skills were tested with a multiple choice questionnaire extracted from Level 1 Spanish Society of Ultrasound Dermatologic Ultrasound accreditation exam before and after the course.

\section{Purpose}

$\nabla$

Dermatologic ultrasound is a recently developed ultrasound application used in the diagnosis and treatment of conditions affecting the skin, hair, and nails $[1,2]$.

The purpose of the study was to evaluate an initial experience with the introduction of training in dermatologic ultrasound in the dermatology component of an undergraduate medical degree.

\section{Materials and Methods \\ $\nabla$}

We offered a complementary theoretical-practical seminar on dermatologic ultrasound to students who are studying dermatology as a subject in the 4 teaching hospitals affiliated with the Faculty of Medicine of Universidad Autónoma de Madrid, Madrid, Spain.

The theoretical component of the seminar $(4 \mathrm{~h})$ consisted of imaging-based sessions in which the
After the course, the students were asked to answer a course evaluation questionnaire

Results: The multiple-choice question scores after the course showed statistically significant improvement (5.82 vs. $8.71 \%$; $<0.001$ ). The questionnaire revealed that students were satisfied with the course, felt that it increased both their dermatologic and ultrasound knowledge, and indicated that they wanted more sonographic hands-on training in both dermatologic ultrasound and other medical fields.

Conclusion: Using both objective and subjective methods, we showed that the introduction of standardized ultrasound training programs in undergraduate medical education can improve both students' understanding of the technique and the quality of medical education in dermatology.

teaching materials were the same as those used in the Basic Dermatologic Ultrasound Course of the Spanish Society of Ultrasound.

In the practical session of the seminar ( $2 \mathrm{~h}$ ), each student was individually trained by a professional sonographer to scan healthy skin, hair, and nails. The instructor explained the examination technique and described the different anatomical planes.

Students were then allowed to scan healthy volunteers, while discussing both the technique and the image content with the instructor.

Before starting the theoretical component, we asked the students to take a multiple-choice questionnaire (MCQ) consisting of 10 questions on anatomical and clinical aspects that were designed to assess baseline knowledge. The questions were taken from the Level 1 Test on Ultrasound in Dermatology of the Spanish Society of Ultrasound.

At the end of the course, we reassessed the students' knowledge using the same MCQs. Each 


\section{QUESTIONS}

The use of sonography helps me to understand skin, nail and hair physiology

The use of sonography helps me to understand skin, nail and hair pathology Ultrasonography is useful to improve physical exam in the dermatologic patient I have acquired confidence in my ability to perform sonographic exams

I think that sonography will motivate me to study the dermatology subject

The seminar has made me consider dermatology as a professional speciality Sonography seminars may help to improve the quality of medical training I would like to learn the application of sonography in other medical specialities I have enjoyed the practice part in sonography seminar

\begin{tabular}{ccc} 
Median Likert score & Mean likert score & \% agree (1-2) \\
1 & 1.65 & $85.71 \%$ \\
1.5 & 1.34 & $94.28 \%$ \\
1 & 1.28 & $100 \%$ \\
2 & 2 & $68.57 \%$ \\
2 & 1.90 & $80 \%$ \\
3 & 3.06 & $28.57 \%$ \\
1 & 1.15 & $100 \%$ \\
1 & 1.03 & $100 \%$ \\
1 & 1.06 & $100 \%$ \\
\hline
\end{tabular}

Table 1 Strongly agree; 2, agree: 3 , neutral; 4, disagree; 5 , strongly disagree. disagree.

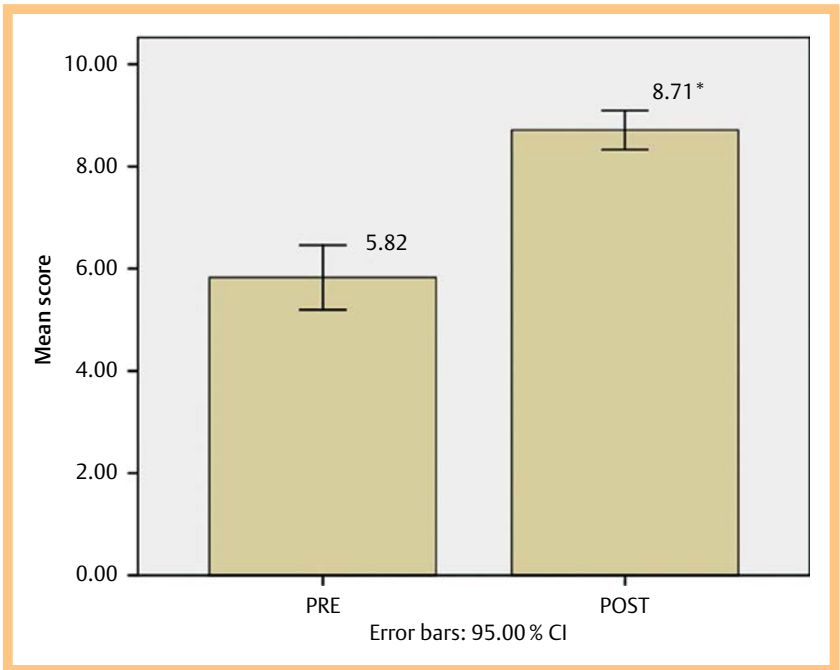

Fig. 1 Sample of MCQ Test of Level 1 Spanish Society of Ultrasound used in Study. MCQ results before ( PRE) and after (POST) workshop * statistically significant.

right answer was given a score of 1 point, and each wrong answer 0 points (total possible score of 10 ).

The students were also asked to evaluate the seminar by completing a Likert scale (LS) questionnaire ( $\bullet$ Table 1) [3].

We collected the scores from the MCQ assessments, and analyzed them using IBM SPSS Statistics for Windows, Version 20.0 (IBM Inc, Armonk, New York, USA). We treated the scores as continuous variables. Since the assumption of normality was rejected using the Shapiro-Wilk test, we used the Wilcoxon signed-rank test to compare median scores before and after the course. A 2 -sided P-value of $<0.05$ was considered statistically significant.

In our evaluation of the seminar, we analyzed the answer scales as continuous variables. We also analyzed the descriptive data and calculated the mean, median, and range, as well as the percentage of students who agreed or strongly agreed with the questions.

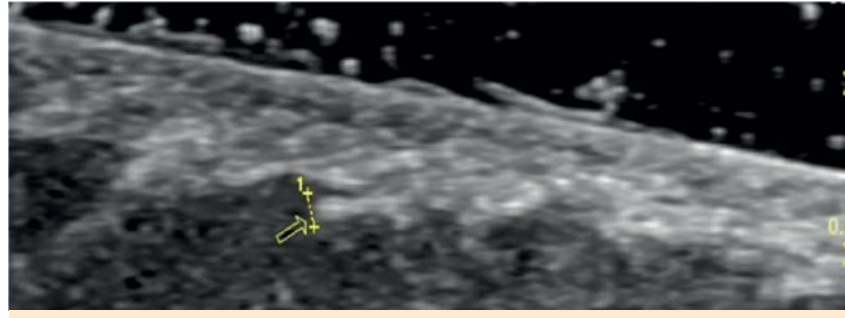

Fig. 2 The subepidermal band has 2 different sonographic areas. What layer is signaled with the white arrow? 1. Papilar dermis; 2 . Reticular dermis; 3. Hair folicle matrix; 4. Hypodermis; 5 . Hair shaft.

\section{Results}

\section{$\nabla$}

A total of 35 students took part in the course, and MCQ scores were available for all 35 students. The mean overall MCQ scores were 5.82 (SD: 1.83) before and 8.71 (SD: 1.13) after the course ( $\bullet$ Fig. 1). The improvement in MCQ scores after the course was statistically significant $(\mathrm{p}=0.021)$.

Most of the students recorded a learning effect, agreeing or strongly agreeing that the seminar improved their skills in physiology of the skin and adnexa ( LS $1.5 ; 85.71 \%$ agree or strongly agree) and in diseases of the skin and adnexa LS $1.3(94.28 \%$ agree or strongly agree). They also felt that the seminar had improved their medical competence in physical examination of the dermatology patient (LS 1.28; $100 \%$ agree or strongly agree) (॰ Fig. 2-4).

$80 \%$ of the students considered that the seminar would motivate them to study dermatology. However, only $28.57 \%$ considered it as a strong motivator for choosing dermatology as a career.

Student perception of the role of practical ultrasound seminars in the quality of their medical training in general and in other specialties was highly positive (LS $1.12 ; 100 \%$, agree or strongly agree).

\section{Discussion \\ $\nabla$}

Dermatologic ultrasound is a recent application that is gradually being adopted by dermatologists [4]. 


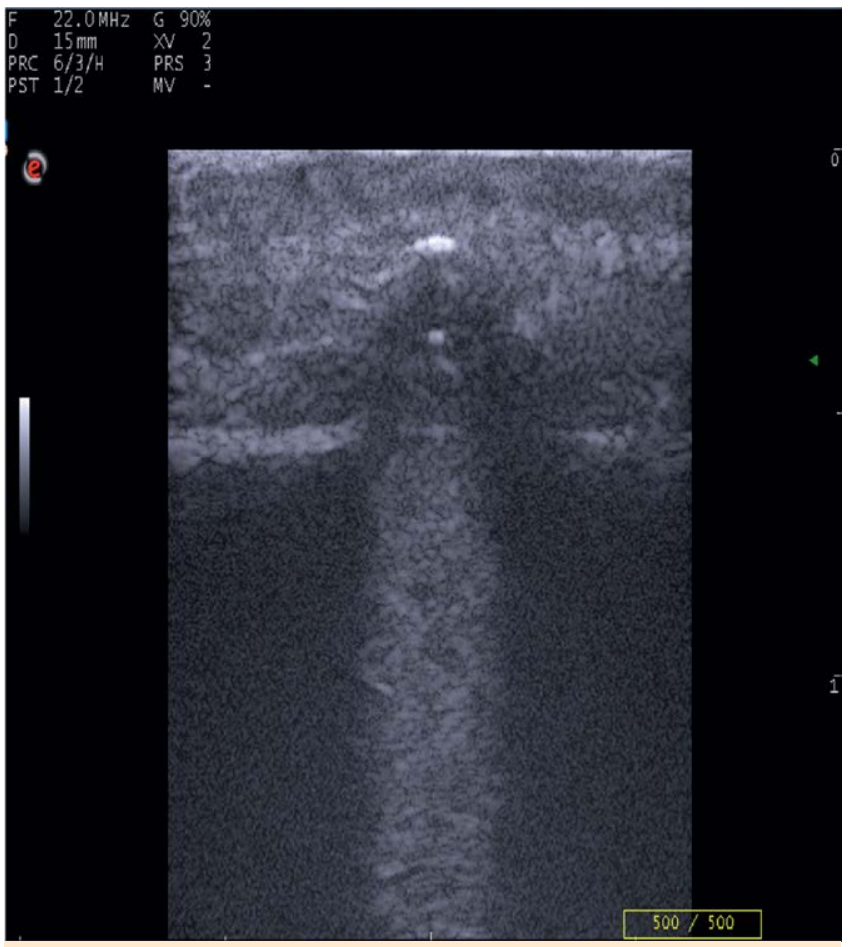

Fig. 3 This image corresponds to a frontal nodule present since the patient was 12 years old. The most likely diagnosis is: 1 . Lupus; 2 . Foreign body; 3. Cyst; 4. Lipoma; 5. Ostema.

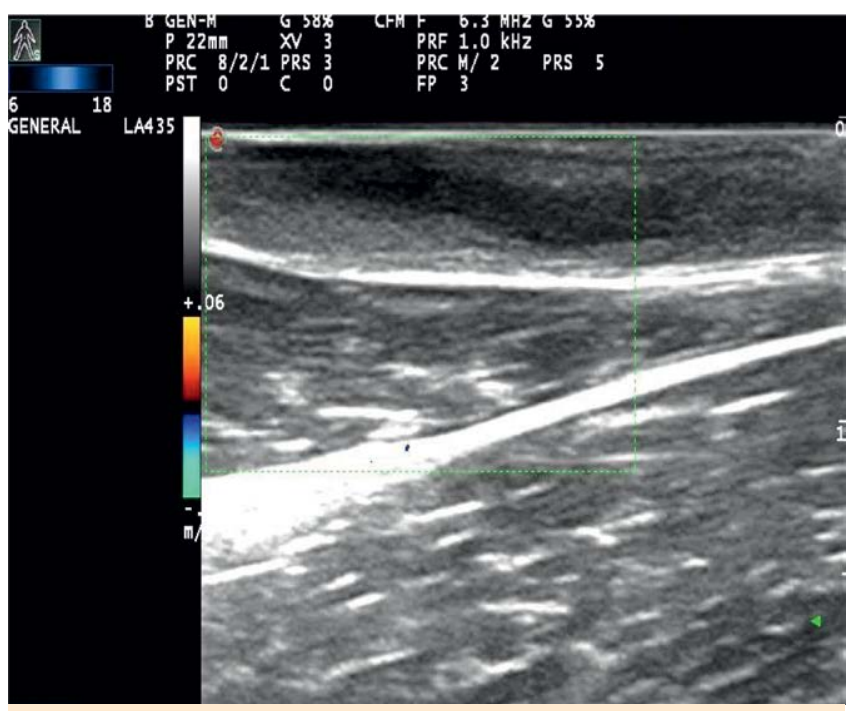

Fig. 4 The most probable diagnosis of this lesion located in the inguinal fold is: 1. Cyst; 2. Pseudocyst; 3. Lipoma; 4. Comedo; 5. Fistulous tract.

We thought that instruction in the technique could help students to better understand the basic anatomy, physiology, and diseases of the skin and its adnexa, while simultaneously providing them with a basic knowledge of ultrasound.

Although research in medical education has its limitations $[5,6]$, mainly owing to lack of randomization and comparison groups and the inherent threats to validity in pretest-post-test studies, some interesting trends can be extracted from our findings:

1) Medical students can improve their knowledge of ultrasound through short training programs.
2) Training programs of this type are very well valued by students who want to increase their background knowledge of ultrasound.

Our results may be inherently flawed by the use of a self-assessment approach, which tends to overestimate the ability of investigational subjects in education and in other areas $[7,8]$. However, we tried to reduce this potential bias through an objective test, which showed better results after the seminar.

With respect to the validity of the test, validity of content and internal structure [9] was based on questions extracted from the Level 1 Test on Ultrasound in Dermatology, which forms part of the accreditation exam of the Spanish Society of Ultrasound, the standard for assessment of a student's ability to use this ultrasound application in Spain.

A possible bias of our evaluation could be the Hawthorne effect [10], which may have increased motivation among the students, who were aware that they were taking part in a study. However, most of the students had no previous knowledge of the technique.

As mentioned in the methods section, the practical, "hands-on" part of the program was not objectively evaluated using a test, and explorations were limited to healthy volunteers. However, the use of clinical and ultrasonographic images of common dermatologic diseases during the seminar could palliate this limitation.

Another limitation was the standardized baseline MCQ. While it could be argued that students would recognize the questions in their post-course evaluation, we did not inform them about the right answers or their scores before or after the course to ensure that they - and students taking the seminar in the future remained blind to the results. A similar approach has been used by other authors $[11,12]$.

Most of the students also considered dermatologic ultrasound to be helpful in studying dermatology as a subject (LS 1.90; $80 \%$ agree or strongly agree). This was one of the main objectives of the seminar. As mentioned above, the integrative role of ultrasound in the gross anatomy and microanatomy, physiology, and diseases of the skin and its visual impact on learning could improve students' understanding of the subject [7].

Students' perception of their confidence in performing ultrasound examinations was also lower than the rest of items with a (LS 2; 68.57\% agree or strongly agree).

This problem could be solved by increasing the number of ultrasound scans using simulators, by increasing the amount of tutors by recruiting students from previous groups [13,14], and by introducing hand-held devices $[15,16]$.

\section{Conclusion}

$\nabla$

Using both objective and subjective methods, we showed that the introduction of standardized ultrasound training programs in undergraduate medical education can improve both students' understanding of the technique and the quality of medical education in dermatology.

\section{References}

1 Wortsman X. Ultrasound in dermatology: why, how, and when? Semin Ultrasound CT MR 2013; 34: 177-195

2 Wortsman X. Common applications of dermatologic sonography. J Ultrasound Med 2012; 31: 97-111

3 Norman G. Likert scales, levels of measurement and the "laws" of statistics. Adv Health Sci Educ Theory Pract 2010; 15: 625-632 
4 Troya $M$, Alfageme $F$. Ultrasound in dermatology: a new approximation to knowledge of the skin. Actas Dermosifiliogr 2015; 106: (Suppl 1): $1-2$

5 Cook DA, Beckman TJ. Reflections on experimental research in medical education. Adv Health Sci Educ Theory Pract 2010; 15: 455-464

6 Fraenkel J, Wallen $N$, Hyun $\mathrm{H}$. How to design and evaluate research in education. New York: McGraw-Hill Education; 2014

7 Eva KW, Regehr G. Self-assessment in the health professions: a reformulation and research agenda. Acad Med J Assoc Am Med Coll 2005; 80: S46-S54

8 Dunning D, Heath C, Suls JM. Flawed self-assessment implications for health, education, and the workplace. Psychol Sci Public Interest 2004; 5: 69-106

9 Ghaderi I, Manji F, Park YS, Juul D, Ott M, Harris I et al. Technical skills assessment toolbox: a review using the unitary framework of validity. Ann Surg 2015; 261: 251-262

10 Sedgwick P, Greenwood N. Understanding the Hawthorne effect. BMJ 2015; 351: h4672

11 Heinzow HS, Friederichs $H$, Lenz P, Schmedt A, Becker JC, Hengst $K$ Marschall B, Domagk D. Teaching ultrasound in a curricular course according to certified EFSUMB standards during undergraduate medical education: a prospective study. BMC Med Educ 2013; 11 13: 84
12 Hamza A, Solomayer E-, Takacs Z, Juhasz-Boes I, Joukhadar R, Radosa $J C$, Mavrova R, Marc W, Volk T, Meyberg-Solomayer G. Introduction of basic obstetrical ultrasound screening in undergraduate medical education. Arch Gynecol Obstet 2016; 294: 479-485

13 Heinzow HS, Friederichs $H$, Lenz P, Schmedt A, Becker JC, Hengst K, Marschall B, Domagk D. Teaching ultrasound in a curricular course according to certified EFSUMB standards during undergraduate medical education: a prospective study. BMC Med Educ 2013; 11 13: 84

14 Arger PH, Schultz SM, Sehgal CM, Cary TW, Aronchick J. Teaching medical students diagnostic sonography. J Ultrasound Med. 2005; 24: 1365-1369

15 Blackstock U, Munson J, Szyld D. Bedside ultrasound curriculum for medical students: report of a blended learning curriculum implementation and validation. J Clin Ultrasound 2015; 43: 139-144

16 Rao S, van Holsbeeck L, Musial JL, Parker A, Bouffard JA, Bridge P, Jackson $M$, Dulchavsky SA. A pilot study of comprehensive ultrasound education at the Wayne State University School of Medicine: a pioneer year review. J Ultrasound Med 2008; 27: 745-749 